\title{
The Socialist Macro-Sect in the 'Digital Age': The Victorian Socialists' Strategy for Assembling a Counterpublic
}

\author{
By lan Anderson
}

RMIT, Melbourne, Australia, ian.ndrsn@gmail.com, jetpack.zoob.net

\begin{abstract}
The Victorian Socialists (VicSocialists) are a socialist electoral organisation in Australia which has had some electoral success as a regional fourth party behind the Greens. This article seeks to address what kind of organisation the VicSocialists are, what communicative techniques the organisation employs in assembling a counterpublic or constituency, and what this case study illustrates in terms of the broader formation of counterpublics in the 'digital age'. This article characterises the VicSocialists as a "macro-sect", a new organisational form. The macro-sect is something more than a socialist micro-sect and less than a mass party, while optimistically conceiving of itself as a proto-mass party. The macro-sect strategy is distinct from another 21st-century party-form, the digital party. Unlike the digital parties, which tend to fetishise digital media, the VicSocialists treat digital media soberly as just one tool in the formation and mobilisation of counterpublics, a tool with serious limitations. Additionally, digital media is complementary with face-to-face communication (such as doorknocking) in important ways. A study of a parallel US macro-sect, the DSA, similarly found that activists were ambivalent about digital media, yet strongly used it for promotion. This commonality with the DSA suggests the international emergence of a new organisational form, with a distinct communicative strategy for forming counterpublics in the so-called 'digital age' - one which necessarily uses digital media, yet does not fetishise it.
\end{abstract}

Keywords: digital parties, macro-sects, communication, digital media, organisation

\section{Author note: COVID and communication}

At the time of writing in late 2020, COVID-19 and associated physical distancing measures have substantially affected communication practices, in particular accelerating the existing trend towards digitisation. Like other organisations, the VicSocialists have come to rely more on digital media for both internal and external communication, and the author is currently working on an analysis of this shift. However, these new developments are beyond the scope of this article, which was researched prior to the outbreak of COVID-19.

\section{Introduction}

This article analyses the Victorian Socialists (VicSocialists), a socialist electoral coalition based in Victoria, Australia. This coalition reached 4-5\% in certain electorates over the 2018 State Election and 2019 Federal Election, coming fourth behind the Greens in those areas. The article asks: what kind of organisation is the Victorian Socialists? What communication practices does this organisation use in assembling a 'public', or constituency? What might this illuminate in terms of the broader formation of (counter)publics in the 'digital age'? My argument is that the Victorian Socialists is a macro-sect, a new kind of socialist organisation in the so-called digital age, one that does not fetishise digital media, instead favouring a mix of communication forms and emphasising face-to-face communication in forming a counterpublic. 
This organisational case study contrasts with other forms such as the 'digital party', but has parallels with at least one international example: the term 'macro-sect' is drawn from recent discussion of US group the Democratic Socialists of America, or DSA (The Regrettable Century 2018). The 'macro-sect' concept contrasts with the concept of the "micro-sect", which was analysed by Marxist theorist Hal Draper (1973). The macro-sect also contrasts with other organisational forms including the digital party, the TV party, and the mass party. My analysis particularly considers how the communicative practices of the VicSocialists are distinct from the 'digital party', another vector of public formation in the digital age. My definition of a digital party here draws on Paolo Gerbaudo's The Digital Party (2018), in which the "digital party" is synonymous with the "platform party" - a party that uses an independent digital platform to structure its internal democracy and organisation. The VicSocialists are not a platform party, most obviously because they do not have a participatory digital membership platform, but also because their philosophy does not elevate the digital as a special space for participatory democracy in general. The organisation uses digital platforms for promotion, reflecting that the web is now the "zero institution" for political work (Dean 2003), an unavoidable bottom line. Yet members do not fetishise digital media, and criticise techno-fetishism. The organisation relies heavily on faceto-face forms, such as doorknocking. Even these practices are complementary with digital media, as illustrated by the use of digital media to organise doorknocking. A study of DSA members' use of social media has parallel results to my own case study, finding that while social media served to widely promote socialist ideas, many activists were also ambivalent about the medium (Barnes 2020). The macro-sects' lack of interest in digital media contrasts with other schools, such as breathlessly techno-utopian work on "postcapitalism" (Mason 2015; Srnicek and Williams 2015), and more sober work on "digital socialism" (Fuchs 2020). Yet despite the technoscepticism of activists, digital media is central to the campaign, complementing other forms of communication and organisation. The case study illustrates that for the socialist 'macro-sect' in the digital age, pre-digital forms of communication continue to be essential, yet digital media has transformed communicative practices and become an unavoidable bottom line - for better or worse.

\section{Literature: Counterpublics in the Digital Age}

My research on the VicSocialists is a contribution to the study of counterpublics in the digital age. This field descends from critical theorist Jurgen Habermas' (1962/1989) work on the "public sphere", an ideal of participatory deliberative democracy that Habermas particularly identifies with the French revolution, and which Habermas argues was "refeudalized" through the development of welfare capitalism. The development from Habermas' "public sphere" to the more pluralised concept of "publics and counterpublics" is associated with socialist feminist Nancy Fraser (1990), who abandoned Habermas' notion of the public sphere as a lost Eden, yet retained it as a normative ideal, while arguing that plural contesting publics are necessary for democracy. For influential sociologist Bruno Latour (2003), assembling "publics" is what defines effective political talk. Queer theorist Michael Warner (2002) underlines that publics form in large part through communicative practices, classically publications, and that counterpublics need their own distinct communicative forms.

As communication is essential for public formation, digital media poses new questions for the field of publics and counterpublics. Case studies of 'digital counterpublics' or 'counterpublics in the digital age' often shy away from a purely utopian or dystopian account of the digital, instead studying how contradictions are negotiated 
in practice (Samuel-Azran 2009; Toepfl and Piwoni 2015; McLaren 2018; Rúdólfsdóttir and Jóhannsdóttir 2018; Roslyng and Blaagaard 2018). Yet the field is not without digital-centrism or underexamined epochal claims, such as Roslyng and Blaagaard's claim that the party form has been superseded by the new "cultural citizen" (2018), not backed up with a broader study of the party form in the contemporary age. Digital Culture scholar Paolo Gerbaudo's (2018) survey of "digital parties" is therefore helpful in considering how the party form has been reworked for the 21st century - examining examples such as the Five Star Movement, Podemos and the Pirate Parties. Although not considering the VicSocialists a digital party, Gerbaudo's analysis is useful in comparatively examining how the party-form is reworked for the 21 st century. Both the VicSocialists and digital parties seek to form new (counter)publics in a context of a crisis of representation, but in different ways. My analysis takes an ethnographic approach in order to understand how VicSocialists activists understand the everyday practices and experiences of activist communication and organisation, while drawing on academic literature to compare this case study with other contemporary cases of public formation.

\section{Literature: The Macro-Sect Form}

A brief genealogy of the sect-form will serve to contextualise my case study on an organisation this article characterises as a 'macro-sect'. The term 'sect' began as a description of religious groups, before being extended to modern political groups. The religious sect is generally one which has broken away from a broader church, and defines itself by its hostility both toward that church and often toward wider society. Similarly, the socialist micro-sects split first from various mass socialist and communist organisations (arguably Trotskyists are to Stalinists as Lutherans are to Catholics), then infamously continued to split in fractal fashion. The macro-sects take the opposite path: rather than emerging from splits, they develop a coalition of existing organisations, and also draw in newly organised layers. A key question is how much they carry on the legacy of the micro-sects, and how much they transcend it. Transcendence would mean the formation of a mass working-class counterpublic, which is often conceived by socialists in terms of the mass party.

The socialist sect-form has been critically analysed by socialists as far back as Marx, if not earlier. Marx defines the sect thusly:

The sect sees the justification for its existence and its "point of honour" - not in what it has in common with the class movement but in the particular shibboleth which distinguishes it from it (1868/1999, emphasis in original).

At this point the distinction between the 'macro-sect' and 'micro-sect' had not been coined. Marxist thinker Hal Draper influentially analysed the "micro-sect" (1973), also decades before the contemporary coinage of the 'macro-sect' - although he did specify the 'micro' part. For Draper, as for Marx, the micro-sect separates itself from the working class through its insistence on an unsullied program. According to Draper, micro-sects tend to be comprised of students, who often take an arrogant and dismissive approach to mass organisations such as trade unions. The solution for Draper is the formation of a broader working-class movement. This requires direct class organising, as well as the development of a communications infrastructure.

In analysing how mass working-class socialist parties are formed, as distinct from micro-sects, Draper refers to the example of the Russian Social Democratic Labour Party (RSDLP)'s newspaper Iskra: 
Iskra was not merely a "literary" enterprise: this is a misunderstanding. A worker in Russia became an "Iskraist" insofar as he agreed with the political views of that political center; and as an "Iskraist" he himself became a political center for further spreading those views in the popular circles in which he worked, in his factory, in his village, in his socialist circle.

However, Draper quickly emphasises that we should not model contemporary organisation directly on the Russian model. Rather, he argues firstly that the socialist activist should engage and organise politically wherever they are (e.g. through the workplace), and secondly that socialists must develop a collective "political centre" (1973), historically something that has been achieved through newspapers. Draper's argument indicates that the question of communication with a public is crucial for the transcendence of the micro-sect form. Of course, the newspaper does not have to be a newspaper: that was just the main form for political communication throughout much of the 20th century. The question is how to develop a form of communication appropriate to the historically specific context one finds oneself in, now the so-called digital age. This article will argue that the VicSocialists as a macro-sect have had some success in their intervention in the digital sphere, despite their ambivalence about 'social media'.

\section{Case study in Historical Context}

This article analyses practices of the Victorian Socialists (VicSocialists), an electoral coalition in Victoria, Australia. The VicSocialists launched in 2018 as a coalition of three socialist groups. That year, the campaign ran a number of candidates for the Victorian parliamentary election (two of the candidates already held seats in local council). They did not meet their goal of electing leading candidate Stephen Jolly to state parliament, but received the fourth largest vote after the Greens. In 2019, the campaign ran three candidates for the Federal Election. Notably their prior leading candidate Jolly was not selected, as the organisation was conducting an investigation for charges of abuse, and after the election he would be suspended over a separate abuse investigation (Towell and Millar 2019). Yet even without this prior leading candidate, the electoral coalition received over $4 \%$ in three electorates.

Before proceeding, a brief historical account will serve to underline why the electoral re-emergence of socialism is significant. Recent decades have seen a decline of engaged 'publics'. Declining public participation in civic and political institutions is associated with "democratic deficit", whereby nominally democratic institutions fail to fulfil democratic functions (Beetham et al. 2002). This can be associated with the decline of grand political narratives, the so-called "End of History" (Fukuyama 1992), and in particular the apparent discrediting of socialist politics. While all forms of public mobilisation declined, this decline particularly affected poor and working-class constituencies, the traditional constituency of left-wing politics. We were not confronted with a lack of socialist groups, quite the contrary - rather socialist groups without publics.

Yet if socialism is dead, a zombie public has recently clawed its way back up. The names Jeremy Corbyn and Bernie Sanders, both marginal backbenchers for a number of decades, are only household names because of newly forming publics. Millenials increasingly identify with socialism (or social democracy), an international pattern that has recently been confirmed in the Australian context with $58 \%$ of millenials 
apparently favouring socialism ${ }^{1}$ (Jones 2018). This has occurred alongside the rise of digital parties, which tend to take more of a 'neither left nor right' stance, but have also assembled a youthful counterpublic of "connected outsiders" (Gerbaudo 2018), alongside the rise of right-wing populists such as Donald Trump. While the mid-term context is one of demobilisation, the short-term context is one of polarisation. Yet judging by the 2019 UK General Election and Bernie Sanders' primary vote, this polarisation has not overall reversed the trend towards broad demobilisation in the wake of neoliberalism. Despite the nascent socialist counterpublic in formation, the question of how to mobilise at sufficient scale remains. The VicSocialists have a strategy for intervening in this conjuncture, distinct from both right-wing populism and digital parties, and my project seeks to map the practice of that strategy. As a 'macrosect', the VicSocialists represent an attempt to turn the historical tide, to assemble a (counter)public in an era where (counter)publics have been disassembled, even to attempt a necromantic revival of the mass party form. The article examines what communication forms the organisation uses in assembling its nascent counterpublic, including the attitude to digital media.

The case study is based on interviews with 13 members and supporters, as well as my own experiences as a member. The project follows principles of "participatory action research" (Trotter and Schensul 1998) or simply Action Research (Greenwood and Levin 1998), an embedded methodology in which the researcher seeks to participate in social change. In line with digital ethnography (Pink et al. 2016), analysis takes a 'non-digital-centric' approach to the digital, treating technology as socially embedded.

\section{The Victorian Socialists as a Macro-Sect}

Like socialist micro-sects, the VicSocialists imagine the socialist mass party as their end goal. The VicSocialists are not nearly as big as fellow macro-sect the DSA, either proportionally or in absolute terms. However, they do fulfil the criteria of being a 'radical reformist' electoral coalition that is broader both politically and in size than the socialist micro-sects. Notably, they 'punch above their weight', achieving an impressive vote for their size, which the component micro-sects likely could not achieve on their own. In other respects the VicSocialists are distinct from the DSA, including their rejection of 'entryism' in centre-left parties in favour of building an independent party (this may be simplified by the Australian electoral system, which has fewer barriers to the entry of third parties than the US does). The VicSocialists are in part a coalition of pre-existing micro-sects along with non-affiliated activists, with many members 'double-carding' with micro-sects, yet restricted from double-carding with other electoral parties. The infrastructure of the micro-sects, particularly Socialist Alternative, was crucial to establishing the VicSocialists quickly for 2018's Victorian state election campaign, before establishing an independent membership structure from early 2019. The question of whether this macro-sect is entirely independent of micro-sects, particularly Socialist Alternative, is unclear and untested, but its membership is certainly broader.

The contemporary macro-sect makes a major step towards wider organisation and communication than the micro-sect. The VicSocialists' coalition comprises both Marxist micro-sects and broader layers, including trade unions and previously unorganised individuals. If micro-sects are largely campus-based, as Draper contends, it

1 It is worth investigating what people understand by 'socialism' here, as definitions are various (Fuchs 2020; Marx 1847/2004). 
may be worth establishing whether the macro-sect has the same sociological basis. Micro-sect Socialist Alternative explicitly theorises a campus-based strategy, arguing that forming a working-class socialist mass party is not yet possible in current conditions (Armstrong 2008). The VicSocialists are politically broader than Socialist Alternative, yet without hard data it is hard to identify whether their activist core is sociologically broader (not quite the same thing as being bigger - the question is the class position of members). My own interviewees tended to be university-educated, but were wage workers in a range of sectors including white-collar and blue-collar sites. Strictly speaking they were working-class in a Marxist sense, selling their labour rather than owning capital, yet the university education of core members may indicate cultural capital in Bourdieu's terms (1986). My study was qualitative rather than quantitative, so it only identifies the class position of my interviewees, not necessarily the organisation as a whole. In terms of quantitative measures, the latter's vote tally in the Northern suburbs indicates broad working-class appeal. This broader appeal, achieved through electoral campaigning and relevant communication practices, distinguishes the macro-sect from the micro-sect. The remainder of the article will consider what communication practices the VicSocialists use as a distinct organisational form.

\section{E-skepticism of Activists}

This comment came from interviewee Kath Larkin, a rail worker who at the time had just been pre-selected as the VicSocialist candidate for Cooper:

I do think sometimes there's an overstatement about social media, like the Arab Revolutions, there were some people who want to refer to them as the Facebook revolutions, but I mean really was the Russian revolution the carrier pigeon revolution? People will find ways to communicate, and actually in that instance people had to find ways to communicate outside of the online forms because the government shut down the internet, and they still organised. ${ }^{2}$

We conducted the interview as the VicSocialists' February 2019 inaugural conference packed up, so it was a relatively short interview. In the background of the recording, I recognise candidate and long-time socialist Sue Bolton calling out some lost property. Around 200 people attended the conference, held at the Maritime Union of Australia headquarters in South Melbourne.

Kath very much emphasised the value of face-to-face communication over the course of the interview, and considers the day-conference a success in bringing people together for democratic deliberation in person. Earlier in the interview Kath commented:

Obviously there's a lot that we do on social media, and I think sometimes when you're in the left you can kind of feel like what you see in your Facebook wall is what everyone sees, but actually we know that's not true, we know that the way that Facebook is manipulated and run means that actually it's quite hard for leftists to get their views out there. I do think social media will still be important particularly for young leftists in the area, but there's also gonna be a need to get out to community events.

${ }^{2}$ It may be worth noting here that her scepticism aligns with debates in academia about the techno-utopianism associated with 'Twitter revolutions' (Dumitru 2012; Berenger 2013; Musa and Willis 2014; Bebawi and Bossio 2014; Kraidy 2016). 
This is a common sentiment among Victorian Socialist activists. VicSocialists volunteer and librarian John Gao had this to say when explaining why he uses Twitter less than he used to:

I guess because I'm interested in politics, not just theoretical but to do stuff in practice, which requires face-to-face interaction, talking to the public in my own city, so therefore organising on a local level is very important, and the absence of that critical mass on Twitter, at least in that area, was not as useful in some ways.

Another interviewee who preferred not to be named commented more bluntly that "Twitter is an actual toilet", and while less anti-Facebook stated that "I don't think we should overstate Facebook because a lot of it was the boots on the ground that did the work."

There was also little interest expressed in a programmatic transformation of digital media. This lack of interest contrasts with other recent work, most strongly the breathless "postcapitalism" school associated with Paul Mason (2015) and Nick Srnicek (2015), which Marxist digital media scholar Christian Fuchs (2015) describes as "one-dimensional" and "techno-determinist". Conversely, Aaron Bastani's arguably similar work on Fully Automated Luxury Communism (2019) is described by Fuchs (2020) as "techno-utopianism without techno-determinism" (18). Fuchs himself takes a more sober approach to the programmatic question of "digital socialism" (2020). VicSocialist activists were simply more interested in other issues, such as migrant worker rights. The 2018 Election Manifesto did not mention digital rights, coming closest to this in a reference to surveillance associated with the War on Terror (VicSocialists 2018). In summary, the VicSocialists activists surveyed did not consider digital media to be the key factor in assembling counterpublics in the 21st century, in contrast to the position taken in (some) literature on the topic.

\section{7....And Yet}

Yet digital media is strongly used for promotion. This reflects that the Internet is a "zero institution" for contemporary political communication (Dean 2003), an unavoidable bottom line, whether fetishised or not. The VicSocialists Facebook page has over 7,000 likes at time of writing. The page averaged 3 original posts a day during the week before the election in 2018 , with posts routinely attracting hundreds of reactions, and regular video posts usually attracting thousands of views. This rate of posts and interactions is similar to the Australian Greens Facebook page over the same period: the Australian Greens are Australia's third largest party, with a relatively significant youth base. VicSocialists also had a number of location-specific Facebook pages, a meme page, an Instagram and a Twitter. The point here is not so much the success of engagement as the effort: despite the activists' stated lack of passion for digital media, there was clearly concerted work to ensure visibility across digital media. Crucially, this was a fairly centralised effort with consistent messaging across major corporate platforms, freeing most activists to engage in other kinds of work and keep their digital engagement to 'likes' and shares. There was no pretension here of digital media as a horizontal structure: it was merely a tool for promotion. Activists' use of digital media as a promotional rather than participatory medium echoes Veronica Barassi and Emiliano Treré's (2012) observation that Italian student activists used 'Web 2.0' technology in a 'Web 1.0' way, for top-down communication rather than 
democratic participation - complicating literature which argues that the affordances of Web 2.0 are participatory.

Additionally, the finding that the VicSocialists are ambivalent about digital media is paralleled by a study on parallel macro-sect the DSA (Barnes 2020). This study found that digital platforms such as Facebook and Twitter served contradictory purposes of cohesion and fragmentation. Interview subjects found the culture on Twitter particularly alienating or even "repellant" $(2020,39-40)$. This is a platform that "skew[s] young, male, well-educated" and tends to use in-jokey humour to promote cohesion, and members expressed concern that this was alienating to those outside the in-group (39-40). Additionally, there is a kind of methodological individualism apparent in many corporate social media platforms. As an alternative "normative strategy", members argued for the use of collective social media pages for promoting socialist ideas, countering the tendency towards individualistic fragmentation (41-43). This is paralleled by the VicSocialists' strong use of centrally administrated pages on Twitter and Facebook, albeit with arguably less emphasis on in-jokey Twitter personalities than for the DSA. It may be worth examining whether the DSA, as a macrosect like the VicSocialists, contrasts with the 'digital parties' in other fashions than in their ambivalence about digital media.

\section{How the VicSocialists Contrast with 'Digital Parties'}

A comparison of the VicSocialists with digital parties can help to illuminate what distinguishes each. A review of Gerbaudo's The Digital Party (2018) by Nina Hall (2019) suggests that Gerbaudo does not adequately compare the digital parties with other contemporary parties:

The book would have benefitted [sic] from painting a broader picture of global trends in political parties and election campaigns [...] a fascinating extension of this book would analyse how parties on the right and the left have used digital technologies to win elections, and engage their members genuinely, or manipulatively, in public debate.

My analysis will therefore offer one comparison between digital parties and a distinct organisational form in the digital age, the socialist macro-sect. This can contribute both to specific characterisation of the macro-sect, and more general comparative study of public formation.

Although the Victorian Socialists strongly use digital media as a tool, they are not structurally a digital party. For Gerbaudo, the digital party is precisely synonymous with the 'platform party' $(2018,69)$ : digital parties developing independent membership platforms such as the various Pirate Parties' LiquidFeedback, Podemos' Participa, and the Five Star Movement's Rousseau (73). The VicSocialists are not a platform party for the rather straightforward reason that they do not operate through an independent, plebiscitary membership platform - any use of digital platforms was promotional rather than plebiscitary. In a platform party, the platform rather than the bureaucracy becomes the intermediary between the leadership and the membership (77). This involves a subordination of content to process (77) not present in socialist parties like the VicSocialists, which subordinate process to politics. Yet the VicSocialists offer significant avenues for member participation, more 'traditional' structures and practices inherited from the 20th-century mass party: face-to-face democratic conferences, doorknocking, and various forms of activist mobilisation. 
One feature the VicSocialists share with digital parties is the attempt to appeal to "connected outsiders". This is Gerbaudo's (2018) term for young educated voters who have substantial access to information technology yet are economically insecure and politically disenfranchised (43-66). If we think of 'connected outsiders' as a nonpublic (due to their outsider status), VicSocialists and the digital parties have divergent strategies for constituting a counterpublic from this conjunctural raw material. In particular, the VicSocialists seek to forge a combined working-class constituency of 'connected outsiders' and 'disconnected outsiders'3, or older working-class voters without the cultural or digital capital of younger constituents - often migrants with English as a second language (one issue an activist raised with reaching out to this constituency is that many couldn't legally vote). Posters and leaflets were translated into languages such as Arabic. Constituting this combined counterpublic requires a diversity of communication tactics, including but not limited to digital media. In interviews, answers to the question of what constituency the VicSocialists appeal to could be sorted into two basic categories: either the broad 'working class', or a combination of inner-city young liberal voters with Northern suburbs older working-class voters, often migrants. Whereas the first of these two answers names a broad counterpublic or 'people', the second is more specific about the populations making up that counterpublic. The second answer is reflected in a Marxist Left Review article by Liz Walsh, a key organiser of the VicSocialists campaign, when she describes it as a "central thesis of the campaign" that "Victorian Socialists could find an audience among not only progressive inner city voters, but also blue collar working class residents" (2019). Participant John Gao expressed a perception that residents of Northern seat Broadmeadows, part of the Northern Metropolitan region targeted by the VicSocialists, were more receptive than those in more central middle-class seats:

I did Broadmeadows as well, that was very different [from Brunswick], much more working-class. And much more disaffection with the economy, much more unemployment and sense of abandonment, so I felt like our message of focusing on working-class needs resonated more in Broadmeadows, which is funny because a lot of my friends who are not involved in Victorian Socialists have this perception that the inner-city suburbs are more left-wing, and the further out you go the more conservative you are, because these friends tend to associate lower socioeconomic class with being more prejudiced maybe? Which is not necessarily true, and I think that was borne out by these conversations, where I would say Broadmeadows residents were more receptive than in Brunswick, where the Broadmeadows residents clearly felt a more desperate need for things to change.

This perception of receptiveness in Broadmeadows was borne out by the numbers, with the party receiving more than $7 \%$ in that area. It's worth underlining here (as VicSocialists activists often did) that the Northern Metropolitan region is strongly migrant, undermining the dichotomisation of anti-racism and working-class politics. This also arguably undermines the construal of the populist right's base as 'working class', which does not match up with stats which establish that their base tend to be economically better-off than the average voter, and more defined by cultural conservatism than economic position (Carnes and Lupu 2017; Inglehart and Norris 2016).

\footnotetext{
3 'Disconnected outsiders' is my term, reworking Gerbaudo's “connected outsiders".
} 
Both the VicSocialists and the digital parties see a return of greater member participation in party processes, yet the form and rate of participation are distinct. Gerbaudo suggests that the growth of membership in digital parties is both due to wider repoliticisation, and the redefinition of membership with a lower barrier to entry (2018, 168). The VicSocialists are one testing ground for this thesis, due to sharing an international political conjuncture with the digital parties, but having a distinct membership structure. Membership in digital parties tends to be highly porous and ambiguous, due in part to the lowered criteria of membership (163). The VicSocialists have established a more traditional paid membership model in contrast to the free membership offered by many digital parties. Digital parties have attracted thousands of members, in some cases hundreds of thousands (162), and treat members as "a resource to be prized rather than merely a source of trouble and even embarrassment" as the TV parties tended to treat members (162). However, Gerbaudo estimates that only about $1 \%$ of members tend to be regularly active (163), By contrast, the VicSocialists have a smaller base but probably a higher proportion of active membership. The digital parties have hundreds of thousands of passive members versus hundreds of active members, whereas the VicSocialists have hundreds of passive members and hundreds of active members - hundreds were mobilised for doorknocking each weekend in the lead-up to the 2018 state election, a significant number for a party formed in the same year that only exists at a state level. In both digital parties and the VicSocialists, the return of strong member participation is a departure from the neoliberal "TV parties" (Gerbaudo 2018, 163), of which they are sharply critical. Like the digital parties, the VicSocialists have seized an opportunity for repoliticisation, left precisely by the depoliticisation of the major parties in Colin Hay's terms - the consignment of decision-making to market fatalism rather than political agency $(2007,90$ 152). This indicates support for Gerbaudo's suggestion that the surge in membership for digital parties is only partly due to their membership structure, and that the other part is a wider repoliticisation $(2018,168)$; in my terms, the return of counterpublics to the electoral sphere. Yet the relatively modest nature of VicSocialists' growth may also affirm that the low barrier to entry in digital parties, closer to the model of Facebook or Twitter than other political parties, is also a significant factor in their rate of growth $(2018,169)$. The requirement that VicSocialists members pay a minimum of $\$ 20$ a year for membership, although not at all onerous by the standards of membership fees generally, is a greater barrier to entry than exists in most digital parties. This higher level of requirement allows the party to cultivate a base of active militants. This is not to deny that the party has passive members, but simply to say that it has a higher proportion of active members than both digital and TV parties, and clearer boundaries of membership than digital parties. There are fewer members, but members are more likely to be active. DSA activists interviewed by Barnes (2020) suggested that a relatively low proportion of their 50,000 members participate in faceto-face organisation. Like the digital parties, the DSA has a significantly larger membership than the VicSocialists. Yet the DSA also have a more traditional membership structure like the VicSocialists, with membership dues required, suggesting a common form distinct from digital parties.

\section{Doorknocking}

VicSocialists activists strongly emphasised the importance of face-to-face work, particularly doorknocking, in reaching the 'disconnected outsiders' of the Northern suburbs. When asked what was required to scale up from a local government to a state level campaign, leading organiser Liz Walsh answered doorknocking first and fore- 
most. More than 95,000 doors were knocked at, with around 120 people attending doorknocking events each weekend for eight weeks (Walsh 2019). Activists express pride in hundreds of activists turning up to doorknocking, and recounted how Green and Labor activists were surprised at how many they mobilised. A report from Marxist Left Review matches accounts from my interviews of successful connections:

It was common for volunteers to return from doorknocking with accounts of meeting old trade union militants keen to regale them about this or that struggle, migrants who had not forgotten their more radical traditions from their country of origin, or even young workers who responded with immediate enthusiasm when we told them our candidate was a construction worker who would only take a skilled worker's wage. These were by no means the majority of experiences, but they indicated there was a constituency to connect with (Walsh 2019).

VicSocialists' success in mobilising hundreds for doorknocking campaigns is a success in face-to-face or 'meatspace' mobilisation, but it is also a success facilitated by digital technology. Doorknockers used an app to record which doors had been knocked, and the events were primarily promoted through Facebook. This illustrates a distinct conception from both utopian and dystopian accounts of digital media - the use of digital media as simply a tool, with pros and cons - also something demonstrated in other 'digital counterpublics' literature. As interviewee Kath Larkin said, "people will find ways to communicate", and digital media is one of those ways. VicSocialists activist and casual academic Daniel Lopez noted that a resident he spoke to on the doorstep in Brunswick had read an article Lopez wrote for US socialist magazine Jacobin, which he found on social media - indicating the way digital connections and face-to-face connections can be complementary. The emphasis on face-to-face communication, given the limitations of digital media, is shared with DSA activists interviewed by Barnes (2020). Therefore this may be a key aspect of the socialist macro-sect, although face-to-face communication remains necessary in all party forms.

\section{Legacy Media}

VicSocialist activists interacted with two distinct strands of 'legacy media' in two distinct ways: with 'mainstream media' such as right-wing newspapers, and with socialist media. Unsurprisingly their engagement with 'mainstream media' was largely critical, although not necessarily dismissive. An example of "oppositional decoding" (to use Stuart Hall's (1973/1993) term) of mainstream media is offered by Kath Larkin's account of daily engagement with newspapers as a rail worker:

One other thing at my workplace is that I clear trains that go to the yard, and people leave newspapers and so we all kind of collect newspapers and then we'll read them in the lunch room, which means we read a lot of Herald Sun, which is obviously a really right-wing news source, but it is useful I think to know what's being said in this newspaper, because it is so widely read.

Activists in general made an effort to engage with 'mainstream media' despite their criticisms. A number of activists spoke of a "blackout"' on coverage of the VicSocialists in mainstream media. This impression of unfavourable terrain is perhaps comparable with the perception of Facebook and Twitter as hostile 
corporate terrain, although those channels afforded more promotion. Of the few articles on the VicSocialists, one article participants often mentioned negatively was a Guardian article which appeared more sympathetic to Fiona Patten, a rival candidate who won the seat Stephen Jolly aimed for.

Although the VicSocialists do not have their own participatory digital platform in the fashion of digital parties, the various component socialist groups do have their own independent print channels. These include newspapers, journals, and websites (discounting social media channels which the groups do not own). Yet these printcentric channels are arguably 'legacy media', perhaps reflecting the fact that the micro-sects are 'legacy organisations', groups that have weathered decades in the cold. Some central activists engaged with socialist media as creators, readers or distributors. Yet this was not universal, with a number of activists not regularly reading the press of organisations like Socialist Alternative - more often, activists reported reading broad left publications like Overland and Jacobin, and some listened to leftleaning podcasts like Chapo Trap House. Daniel Lopez, a central organiser in the Preston region and a member of Socialist Alternative at time of interview - he remains involved in VicSocialists - reported not reading Socialist Alternative's publication Red Flag because it was easy to predict what the organisation's take would be. He also expressed a view that Red Flag had not adequately taken the opportunity presented by the VicSocialists campaign. I myself had a subscription for a year but never got around to reading it, then didn't renew. Therefore, although a number of activists did engage with socialist media, it didn't appear to be particularly complementary with the VicSocialists campaign, with the exception of electoral propaganda on digital media channels - which is counterintuitive, given activists' stated scepticism about these channels. This is likely due to the relative efficiency of social media channels compared with newspapers. More recently, that is after the VicSocialists' State and Federal election campaigns, Socialist Alternative launched a podcast called Red Flag Radio, taking advantage of the wider wave of socialist podcasts such as Chapo Trap House. Unlike the micro-sects, and like fellow macro-sect the DSA, the VicSocialists do not have a distinct newspaper, although many activists engage with popular, unaffiliated US socialist publication Jacobin. In the contemporary macro-sect form, digital platforms arguably supersede newspapers, even in the case of Jacobin, which is more widely read in its online form.

If we also include snail mail, posters, yard signs and the like as 'legacy media' due to pre-existing digital media, then these forms of legacy media were perceived as decisive, unlike the socialist newspapers. Campaign organiser Liz Walsh makes this case:

The numbers of doors knocked on, letters distributed, corflute/yard signs erected, posters plastered on street poles and so on is absolutely decisive in being able to connect up with the left wing sentiment and discontent with the major parties that does exist among layers of people in Victoria (2019).

To demonstrate this case, Walsh points to the example of the Western Metro region, which had similar demographics to Northern Metro but where the VicSocialists didn't wage a ground campaign. Here the VicSocialists received $0.57 \%$ of the vote (2019). Therefore the ground campaign was decisive in the VicSocialists' more impressive result in Northern Metro. This arguably vindicates the VicSocialists activists' strong emphasis on doorknocking and other 'old-school' methods, without eschewing digital 
communication. Walsh's article, which is fairly extensive, does not mention social media either positively or negatively (2019).

Although the VicSocialists and the digital parties had distinct approaches to internal participation, it may be that their approach to promotion is similar, shaped more by the necessities of the existing communications infrastructure than by conscious ideology. The emphasis on doorknocking is not a complete refusal of that default, as digital media in practice remains central to the campaign and even to the doorknocking infrastructure. Yet the VicSocialists refuse to rely primarily or exclusively on that default, based on an argument that it is insufficient to develop a socialist counterpublic, and sometimes actively counterproductive.

This ongoing use of pre-digital forms is not unique to the VicSocialists. Gerbaudo (2018) notes in one sentence that digital parties still employ "traditional" party methods such as doorknocking (163). This is not nothing: doorknocking is a significant organisational commitment. Although Gerbaudo's survey of digital parties is generally strong, he emphasises the newness of the digital, and does not dedicate sufficient attention to the complementarity of digital media with older forms of communication and organisation. This is in line with limitations in the 'digital counterpublics' literature, with its arguable digital-centrism (although Gerbaudo does not use the postHabermasian concept of 'counterpublics'). In the VicSocialists, media is embedded but not fetishised, and is complementary with other forms of communication. This complementarity may still be a factor in other organisational forms, even those that fetishise the digital. Certainly digital media is complementary with non-digital communication in the socialist macro-sect.

\section{Conclusion}

This article considered what kind of organisation the Victorian Socialists are. The case study ethnographically described their communication practices in forming a counterpublic, and considered what this might illuminate in terms of the broader formation of publics in the so-called digital age. The VicSocialists have a distinct strategy for reviving the party-form, one which contrasts with digital parties. Sharing a conjuncture, the digital parties and the VicSocialists do have tactical elements in common; most obviously the use of digital media for promotion, but also the appeal to 'connected outsiders' as a counterpublic, and the criticism of 'TV parties' that have hollowed out active membership. These common features are likely due to a common techno-political conjuncture, as well as the newness of both organisational forms, rather than a common philosophy. Yet they are also strategically distinct in key respects, most crucially the lack of digital process fetishism in VicSocialists, the emphasis on continuing pre-digital communication forms as a way of constituting a counterpublic, and the attempt at a necromantic revival of mass-party socialism. VicSocialist activists emphasise the importance of face-to-face organisation, although in practice digital media and other forms of organisation are strongly complementary. The case study illustrated that pre-digital forms of communication continue to be important, without undercutting that digital media has transformed communicative practices.

The article characterised the Victorian Socialists as a macro-sect, an organisational form that has a distinct approach to forming counterpublics in the digital age. The concept of the 'macro-sect' is borrowed from analysis of the Democratic Socialists of America (The Regrettable Century 2018), and contrasts with the 'micro-sects' analysed by Marxist theorist Hal Draper (1973). The macro-sect is something more than a micro-sect and less than a mass party. In common with the micro-sect, the 
macro-sect emphasises programmatic principles as a defining difference from other organisations, and its leadership may still be composed of university-educated intellectuals. In contrast to the micro-sect, the macro-sect is multi-tendency, broader in terms of membership, and cultivates a working-class base through its electoral activities and communication practices. Also unlike Marxist micro-sects, neither the VicSocialists nor the DSA have their own newspapers, a 20th-century legacy form of communication - yet activists from both organisations tended to engage with popular socialist magazine Jacobin, which is not officially affiliated to any one organisation. Both organisations also strongly use digital media; yet, like VicSocialist activists, DSA activists are ambivalent about corporate social media (Barnes 2020). DSA members argued for collective social media pages to counter the social media tendency towards individualist fragmentation (Barnes 2020), a strategy also used by the VicSocialists with its public pages. Further studies could elaborate common or divergent experiences and practices, as in this article's comparison of the VicSocialists with both the DSA and the digital parties. Although the VicSocialists and the DSA crucially share an ambivalence about digital media, more investigation would be needed to establish if the DSA contrasts with 'digital parties' in other respects, as the VicSocialists do. My development of the 'macro-sect' concept contributes to the broader study of counterpublic formation in the digital age, outlining a distinct kind of public formation. A remaining question is whether the macro-sect is scalable, or will remain something bigger than the micro-sect but smaller than the mass party - whether the nascent counterpublic can reach the scale required to have lasting institutional impact.

\section{References}

Armstrong, Liam. 2018. Could Steve Jolly Be Australia's First Socialist Politician in 70 Years? Vice, February 8. Accessed June 18, 2018. https://tinyurl.com/yxvipsak

Armstrong, Mick. 2008. From Little Things Big Things Grow. Socialist Alternative. Accessed April 4, 2020. https://www.sa.org.au/node/4002

Barassi, Veronica and Emiliano Treré. 2012. Does Web 3.0 come after Web 2.0? Deconstructing theoretical assumptions through practice. New Media \& Society 14 (8): 12691285.

Barnes, Christopher C. 2020. Democratic Socialists on Social Media: Cohesion, Fragmentation, and Normative Strategies. tripleC: Communication, Capitalism \& Critique 18 (1): 1 285. Accessed February 29, 2020. https://tinyurl.com/set6plj

Bastani, Aaron. 2019. Fully Automated Luxury Communism: A Manifesto. London: Verso.

Berenger, Ralph D., ed. 2013. Social Media go to War: Rage, Rebellion and Revolution in the Age of Twitter. Phoenix, AZ: Marquette Books LLC.

Beetham, David, Sarah Bracking, lain Kearton, Nalimin Vittal and Stuart Weir, eds. 2002. The State of Democracy: assessments in eight nations around the world. The Hague: Kluwer Law International.

Bebawi, Saba and Diana Bossio, eds. 2014. Social Media and the Politics of Reportage: The 'Arab Spring'. Basingstoke: Palgrave Macmillan UK.

Bourdieu, Pierre. The Forms of Capital. 1986. In Handbook of Theory of Research for the Sociology of Education. Westport, CT: Greenwood.

Carnes, Nicholas and Noam Lupu. 2017. It's time to bust the myth: Most Trump voters were not working class. Washington Post, June 5. Accessed April 22, 2018.

https://tinyurl.com/ybmv7lel

Dean, Jodi. 2003. Why the Net is Not a Public Sphere. Constellations 10 (1): 95-112. 
Draper, Hal. 1973. Anatomy of the Micro-Sect. Unpublished document circulated privately in 1973; reprinted from the Center for Socialist History by Marxists.org. Accessed October 6, 2020. https://www.marxists.org/archive/draper/1973/xx/microsect.htm

Dumitru, Cristea. 2012. The Role of Information Technology and Communications in the Development of the Arab Spring Riots. Annals: Series on Military Sciences 4 (1): 24-32.

Fraser, Nancy. 1990. Rethinking the Public Sphere: A Contribution to the Critique of Actually Existing Democracy. Social Text 25/26: 56-80. Accessed March 12, 2018. https://www.jstor.org/stable/466240

Fuchs, Christian. 2015. Henryk Grossman 2.0: A Critique of Paul Mason's Book "PostCapitalism: A Guide to Our Future". tripleC: Communication, Capitalism \& Critique 16 (1): 232243. Accessed March 20, 2020. https://www.triplec.at/index.php/tripleC/article/view/757/841

Fuchs, Christian, ed. 2020. Communicative Socialism/Digital Socialism. tripleC: Communication, Capitalism \& Critique 18 (1): 1-285. Accessed February 29, 2020. https://tinyurl.com/set6pli

Fukuyama, Francis. 1992. The End of History and the Last Man. Free Press.

Gerbaudo, Paolo. 2018. The Digital Party: Political Organisation and Online Democracy. London: Pluto Press.

Greenwood, Davydd J. and Morten Levin. 1998. Introduction to action research: social research for social change. Thousand Oaks: Sage Publications.

Habermas, Jurgen. 1962/1989. The Structural Transformation of the Public Sphere: An enquiry into a category of bourgeois society. Translated by Thomas Burger and Frederick Lawrence. Cambridge, MA: MIT Press.

Hall, Nina. 2019. Paulo Gerbaudo, The Digital Party: Political Organisation and Online Democracy [review]. International Sociology 34 (5): 624-628.

Hall, Stuart. 1973/1993. Encoding, Decoding. In The Cultural Studies Reader [2nd edition], edited by Simon During, 90-103. London: Routledge.

Hay, Colin. 2007. Why We Hate Politics. Cambridge: Polity Press.

Hutchby, lan. 2001. Technologies, Texts and Affordances. Sociology 35 (2): 441-456.

Inglehart, Ronald F. and Pippa Norris. 2016. Trump, Brexit, and the Rise of Populism: Economic Have-Nots and Cultural Backlash. Faculty Research Working Paper Series, Harvard Kennedy School.

Jones, Alan. 2018. Australian youth lurching left: $58 \%$ of millennials favour socialism. $2 \mathrm{~GB}$ [radio station], June 21. Accessed June 22, 2018. https://tinyurl.com/yybhx3fm

Kraidy, Marwan M. 2016. The naked blogger of Cairo: Creative insurgency in the Arab world. Harvard University Press.

Latour, Bruno. 2003. What if We Talked Politics a Little? Contemporary Political Theory 2 (2): 143-164.

Marx, Karl. Manifesto of the Communist Party. 1848/2004. Originally translated by Samuel Moore and Frederick Engels; transcribed from Marx/Engels Selected Works, Vol. One, Progress Publishers, Moscow, 1969, pp. 98-137 by Zodiac and Brian Baggins for Marxists.org. Accessed October 6, 2020. https://tinyurl.com/opzl2g2

Marx, Karl. 1868/1999. Letter from Marx to Schweizer In Berlin. In Marx and Engels Correspondence, Progress Publishers 1986; translated by Donna Torr; transcribed by Sally Ryanin for Marxists.org. Accessed April 10, 2020. https://www.marxists.org/archive/marx/works/1868/letters/68 10 13-abs.htm

Mason, Paul. 2015. PostCapitalism: A Guide to Our Future. London: Allen Lane.

McLaren, Peter. 2018. Gangsta Pedaogogy and Ghettocentricity: The Hip Hop Nation as Counterpublic Sphere. In Revolutionary Multicululturalism: Pedagogies of Dissent for the New Millenium, edited by Peter McLaren. Abingdon: Routledge.

Musa, Bala A. and Jim Willis. 2014. From Twitter to Tahrir Square: Ethics in social and new media communication. Santa Barbara: Praeger. 
Pink, Sarah, Heather A. Horst, John Postill, Larissa Hjorth, Tania Lewis and Jo Tacchi. 2016. Digital Ethnography: Principles and Practice. Los Angeles: Sage Publications.

Roslyng, Mette Marie and Bolette B. Blaagaard. 2018. Networking the political: On the dynamic interrelations that create publics in the digital age. International Journal of Cultural Studies 21 (2): 124-138.

Rúdólfsdóttir, Annadís and Ásta Jóhannsdóttir. 2018. Fuck patriarchy! An analysis of digital mainstream media discussion of the \#freethenipple activities in Iceland in March 2015. Feminist Psychology 28 (1): 133-151.

Samuel-Azran, Tal. 2009. Counterflows and counterpublics: The al-Jazeera effect on Western Discourse. Journal of International Communication 15 (1): 56-73.

Srnicek, Nick and Alex Williams. 2015. Inventing the Future: Postcapitalism and a World Without Work. London: Verso.

The Regrettable Century. 2018. Not With A Bang, But With a Purge, a Split and a Public Statement: The Death of the Micro Sect. The Regrettable Century [podcast]. Accessed October 23, 2018. https://tinyurl.com/y65rlhbe

Toepfl, Florian and Eunike Piwoni. 2015. Public Spheres in Interaction: Comment Sections of News Websites as Counterpublic Spaces. Journal of Communication 65 (3): 465-488

Towell, Noel and Benjamin Millar. 2019. Stephen Jolly splits from Victorian Socialists amid serious allegations. The Age, 23 September. Accessed October 7, 2019. https://tinyurl.com/yxu3gyvk

Trotter, Robert and Jean J. Schensul. 1998. Methods in Applied Anthropology. In Handbook of methods in cultural anthropology, edited by $\mathrm{H}$. Russel Bernard. Walnut Creek: AltaMira Press.

VicSocialists. Manifesto. 2018. Accessed December 16, 2019. https://www.victoriansocialists.org.au/manifesto

Warner, Michael. 2002. Publics and counter-publics. Public Culture 14 (1): 49-90.

Walsh, Liz. 2019. Launching Victorian Socialists: an anti-capitalist electoral alliance. Marxist Left Review 18: 19-38.

Weber, Max. 2015/1912. Classes, Stände, Parties. In Weber's Rationalism and Modern Society: New Translations on Politics, Bureaucracy and Social Stratification, translated and edited by Tony Waters and Dagmar Waters, 37-59. London: Palgrave Macmillan.

\section{About the Author}

\section{lan Anderson}

lan Anderson, aka Ani White, is a Doctoral Candidate at RMIT Melbourne, and a member of the Victorian Socialists. They are Australia New Zealand spokescouncil member and editor for Interface: a journal for and about social movements. They are also an editor for the socialist magazine Fightback (fightback.org.nz), and contribute to the politics and pop culture podcast Where's My Jetpack?! (jetpack.zoob.net). They are interested in media and communication, the formation of counterpublics, and socialist politics. 